\title{
Introduction to Cardiac Neuronal Imaging: A Clinical Perspective
}

\author{
Arnold F. Jacobson and Jagat Narula \\ Icahn School of Medicine at Mount Sinai, New York, New York
}

\begin{abstract}
Procedures for noninvasive and minimally invasive imaging of cardiac neurons and neuronal function using radiolabeled compounds were developed in the second half of the 20th century. The foundation for these procedures was several centuries of research that identified the structural components of the autonomic nervous system and explored the means by which neurotransmitters such as acetylcholine and norepinephrine contributed to neuronal control of target organ effector cells. This article provides a brief clinical overview of modern approaches to the assessment of cardiac neurons as an introduction to the in-depth articles on the current status of cardiac neuronal imaging presented in this supplement.
\end{abstract}

Key Words: autonomic nervous system; cardiac neuronal imaging; SPECT; PET

J Nucl Med 2015; 56:3S-6S

DOI: 10.2967/jnumed.114.150458

$\mathbf{T}$

he importance of the role of the autonomic nervous system as a regulator of human physiologic balance and homeostasis has been appreciated for several centuries. Most of the early discoveries about this system were based on results of anatomic dissections; later research included the use of mechanical, electrical, and pharmacologic stimulation to elicit neurologic responses (1). In the 20th century, improvements in analytic techniques allowed more accurate in vitro measurements of neurotransmitters such as acetylcholine, epinephrine, and norepinephrine, which provided further understanding of the interactions and responses of the parasympathetic and sympathetic systems $(2,3)$. The use of radiolabeled versions of these neurotransmitters later offered a means to monitor in vivo pharmacodynamics and provided the first quantitative estimates of uptake and clearance of these compounds in living tissues $(4,5)$. Research with compounds labeled with tritium $\left({ }^{3} \mathrm{H}\right),{ }^{14} \mathrm{C}$, and ${ }^{125} \mathrm{I}$ laid the groundwork for the development of compounds labeled with $\gamma$ - and positron-emitting radioisotopes ( 6 ). These latter developments permitted external imaging of living animals with scintillationdetection devices and gave rise to the use of nuclear medicine techniques for neuronal imaging in the second half of the 20th century (7-10).

To appreciate the strides made in imaging of the cardiac sympathetic nervous system in the past $30 \mathrm{y}$, it is necessary to understand the

Received Feb. 5, 2015; revision accepted Apr. 2, 2015.

For correspondence or reprints contact: Jagat Narula, Icahn School of Medicine at Mount Sinai, One Gustave L. Levy PI., New York, NY 10029.

E-mail: narula@mountsinai.org

COPYRIGHT (c) 2015 by the Society of Nuclear Medicine and Molecular Imaging, Inc. foundational research on norepinephrine kinetics in sympathetic nerves. Much of this research involved measurement of norepinephrine turnover, a quantitative method for estimating sympathetic nerve function that has been widely used in both animal and human subjects (6). The best validated method of measuring norepinephrine turnover involves injecting radiolabeled ${ }^{3} \mathrm{H}$-norepinephrine and measuring its initial uptake and then its disappearance from the heart and other organs over several hours $(5,11)$. Studies in animals have shown that, in a variety of physiologic and pathophysiologic situations, ${ }^{3} \mathrm{H}$-norepinephrine disappearance from the heart follows first-order kinetics, which can be characterized in terms of a fractional turnover rate, $\mathrm{k}$, or turnover half-time, T1 (12). By analogy, subsequent imaging measurements using norepinephrine analogs such as metaiodobenzylguanidine (MIBG) for SPECT and metahydroxyephedrine (MHED) for PET have sought to provide similar estimates of organ turnover as a means to discern neuronal system function in health and disease $(9,13)$. The potential value of such information resides in its usefulness for disease quantification in general, and more specifically, in its use to estimate prognosis and likely response to therapy - both current standard of care and future cutting-edge pharmacologic, device, and genetic treatment procedures.

Because of the enormous potential value of in vivo quantitative information on the status of the autonomic nervous system, it is somewhat puzzling that clinical practitioners-and more specifically, clinical cardiologists - have been resistant to incorporating new imaging procedures into assessment and treatment algorithms and clinical guidelines. The main imaging agents in this field, ${ }^{123} \mathrm{I}-\mathrm{MIBG}$ and ${ }^{11} \mathrm{C}-\mathrm{MHED}$, have both been widely studied for $30 \mathrm{y}$, and ${ }^{123} \mathrm{I}-\mathrm{MIBG}$ has been used in clinical cardiology in Japan and, to a lesser extent, in Europe, for 2 decades $(10,13,14)$. There is no shortage of quality data on the effect of various diseases on uptake and clearance of these agents from the heart, and many studies have shown that the imaging results are predictive of both the likelihood of therapeutic response and the relative risk for various adverse outcomes despite apparently optimal, guidelines-based therapy (15-18). What then is missing from the published literature to convince cardiology thought-leaders that the imaging information is not only valuable but also actionable? The most common response to this question is that there are insufficient data documenting clinical utility. In other words, data are needed that demonstrate a better clinical outcome for patients who are studied with these procedures than comparable patients who are treated without access to this information.

This supplement presents an update on the status of autonomic nervous system imaging of the heart from experts in the field. The primary focus is on the sympathetic system and potential clinical applications of the imaging methodologies. This article provides a brief historical perspective for the more in-depth examinations that follow. 


\section{NOREPINEPHRINE}

As noted previously, characterization of tissue content and turnover of norepinephrine in vivo has been extensively studied using ${ }^{3} \mathrm{H}$-norepinephrine. Under conditions of a steady-state infusion of this radiolabeled compound, spillover rate can be determined on the basis of the ratio of the infused radioactive norepinephrine concentration and the measured plasma norepinephrine specific activity (Fig. 1) (7,11). Cardiac spillover can be measured by intracoronary infusion of ${ }^{3} \mathrm{H}$-norepinephrine and sampling of the coronary sinus blood for radioactivity content. Although this method provides a total estimate of norepinephrine spillover, the relative contributions of decreased neuronal uptake and increased turnover cannot be determined using this technique, and its invasive character makes it unsuitable for use as a routine clinical diagnostic procedure.

Early efforts to produce compounds that would allow in vivo imaging of norepinephrine biologic behavior were primarily focused on direct labeling of neurotransmitters such as epinephrine and norepinephrine and the use of false neurotransmitters that were not as readily metabolized as the catecholamines. Several compounds were successfully labeled with ${ }^{11} \mathrm{C}$ for PET imaging, including norepinephrine and epinephrine and the false neurotransmitters ephedrine and MHED $(7,10)$. Later work using ${ }^{18} \mathrm{~F}$ as the radiolabel resulted in the synthesis of fluorodopa and fluorodopamine for sympathetic neuronal imaging (9). For conventional $\gamma$-camera imaging, the false neurotransmitter guanethidine was used as the structural basis for several iodine-labeled agents, the most successful of which was MIBG, developed by Wieland et al. $(19,20)$ and Raffel and Wieland (21). During the past $30 \mathrm{y}$, imaging with ${ }^{18} \mathrm{~F}$ fluorodopamine has provided data for the in vivo assessment of norepinephrine synthesis, whereas ${ }^{11} \mathrm{C}$-MHED, ${ }^{11} \mathrm{C}$-ephedrine, and ${ }^{123} \mathrm{I}-\mathrm{MIBG}$ have been extensively used to estimate the presynaptic reuptake and storage behavior of norepinephrine $(7,9,10)$.

More limited work has been done to investigate the postsynaptic receptors in the myocardium. This has primarily involved PET imaging using labeled $\beta$ blockers such as ${ }^{11} \mathrm{C}$-(4-(3-t-butylamino2-hydroxypropoxy)-benzimidazol-1) and ${ }^{18}$ F-fluorocarazolol (Fig. 2) (10). Postsynaptic muscarinic receptors have also been imaged using the compound ${ }^{11} \mathrm{C}$-methylquinuclidinyl benzylate (7). Although results using these and similar agents have provided valuable insights into the effects of various cardiac disease processes on receptor density and function, it is unclear whether this type of imaging will have clinical applications in the foreseeable future.

\section{I-MIBG}

Of all cardiac neuronal imaging agents, the one with the greatest research and clinical experience is ${ }^{123}$ I-MIBG. Hundreds of research studies and tens of thousands of clinical examinations have been performed since the compound was developed more than $35 \mathrm{y}$ ago at the University of Michigan $(13,15,21)$. ${ }^{123}$ I-MIBG scintigraphy identifies tissues capable of concentrating neuroadrenergic amines, thereby providing a means to document the loss of autoregulatory sympathetic neuronal function (22). In the heart, ${ }^{123}$ I-MIBG imaging can identify sympathetic neuronal injury that may not be apparent from other functional or anatomic imaging examinations (23).

During the past $25 \mathrm{y}$, studies have shown that the degree of reduction of cardiac ${ }^{123}$ I-MIBG uptake is related to the severity of heart failure and the subsequent prognosis (24-28). ${ }^{123} \mathrm{I}-\mathrm{MIBG}$ imaging can also be used for assessing response to any therapies used to treat heart failure, including angiotensin-converting-enzyme inhibitors (29), angiotensin receptor blockers (30), $\beta$ blockers (31), aldosterone inhibitors (32), and devices such as biventricular pacemakers for cardiac resynchronization (33) or left ventricular assist devices (34). Heart failure patients with moderate to severely reduced myocardial ${ }^{123} \mathrm{I}-\mathrm{MIBG}$ uptake as a reflection of myocardial denervation have the poorest outcomes $(27,28,35)$, in terms of morbidity and mortality from pump failure as well as from unstable arrhythmias that often precede the occurrence of sudden cardiac death (Fig. 3) $(36-38)$

\section{CONCLUSION}

Because derangements of cardiac innervation are common in most heart diseases, and because heart failure is a chronic condition that affects more than 5 million patients in the United States (39), there is a compelling reason to identify the clinical circumstances under which imaging of neuronal function is ben-
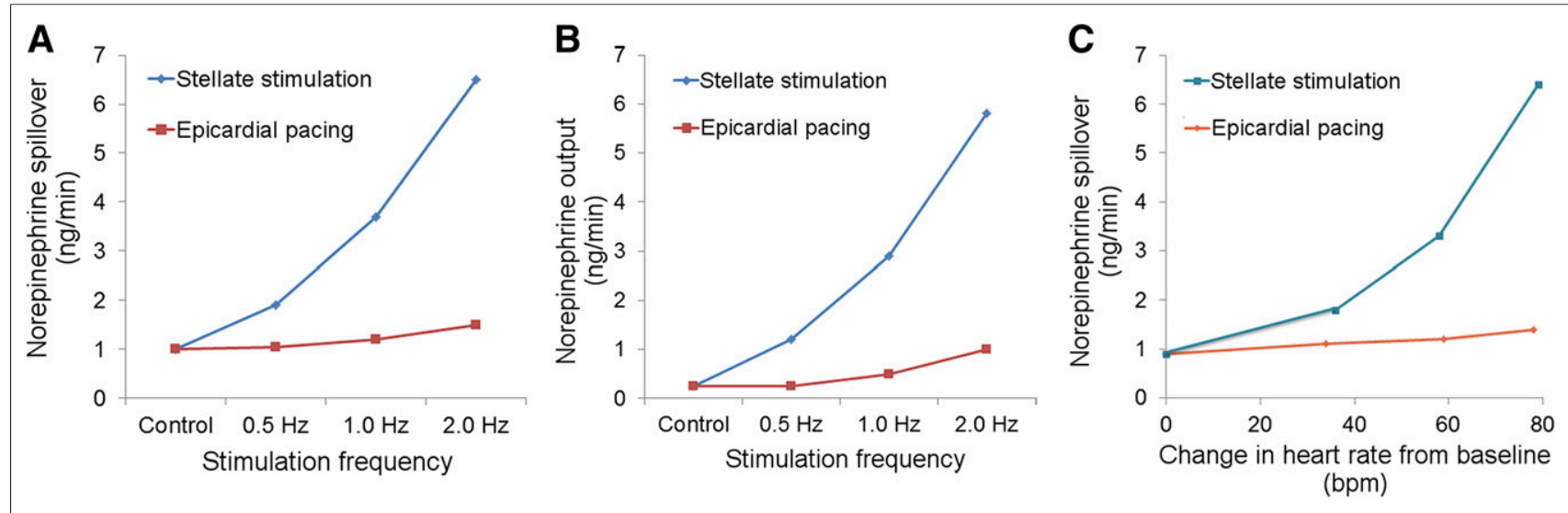

FIGURE 1. Results of studies with ${ }^{3} \mathrm{H}$-norepinephrine in dogs. Effects of stimulation of stellate ganglion and epicardial pacing on dogs receiving steady-state infusion of labeled norepinephrine are shown. (A) Ganglionic stimulation produced a much greater increase in norepinephrine spillover compared with pacing. (B) Ganglionic stimulation produced a similar greater increase in norepinephrine output compared with pacing. (C) For similar increases in heart rate versus control, cardiac norepinephrine spillover was much greater for ganglionic stimulation than for epicardial pacing. These results confirm strong correlation between norepinephrine spillover and sympathetic outflow to heart and that norepinephrine spillover is not primarily a reflection of heart rate changes. (Adapted from (11).) 


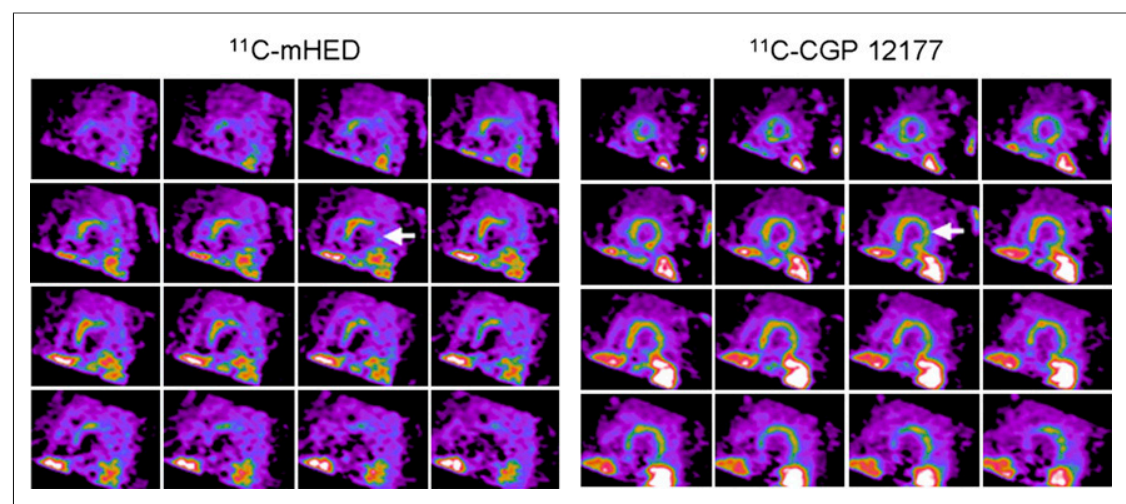

FIGURE 2. Short-axis PET images of presynaptic function ( $\left.{ }^{11} \mathrm{C}-\mathrm{MHED}\right)(\mathrm{A})$ and postsynaptic $\beta$ receptors ( ${ }^{11} \mathrm{C}$-(4-(3-t-butylamino-2-hydroxypropoxy)-benzimidazol-1)) $\left({ }^{11} \mathrm{C}-\mathrm{CGP}\right.$ 12177) (B) in heart failure patient. Apical slices are at upper left and basal slices are at lower right of each panel. Presynaptic neuronal uptake is more severely impaired than postsynaptic receptor uptake, with large area of mismatch indicated by arrows. Severity of such preand postsynaptic mismatch may relate to likelihood of adverse cardiac outcomes. (Reprinted from (10).)
The articles in this supplement summarize the current thinking of cardiology and imaging experts. The essential message is that imaging of neuronal function provides new information about a fundamental physiologic attribute of the heart that is complementary to the results of other standard imaging and in vitro methods currently used by clinicians as part of routine clinical care. The ultimate beneficiary of cardiac neuronal imaging will be the patient, who will not only have a better understanding of the severity of his or her heart condition but will also be better equipped to judge whether the potential benefits of the proposed therapeutic options are sufficient to justify any associated risks.

\section{DISCLOSURE}

No potential conflict of interest relevant to this article was reported. eficial. It is evident that quantitative measures of the condition of the cardiac nervous system can provide useful supplementary information for the clinician. In the same way that assessment of myocardial perfusion supplements anatomic information on the status of the coronary arteries, assessment of myocardial innervation adds to the information provided by functional and anatomybased techniques such as echocardiography, CT, and cardiac MR imaging. The challenge is to define the patient populations for whom neuronal imaging has the greatest benefit for improving quality of life and clinical outcome.

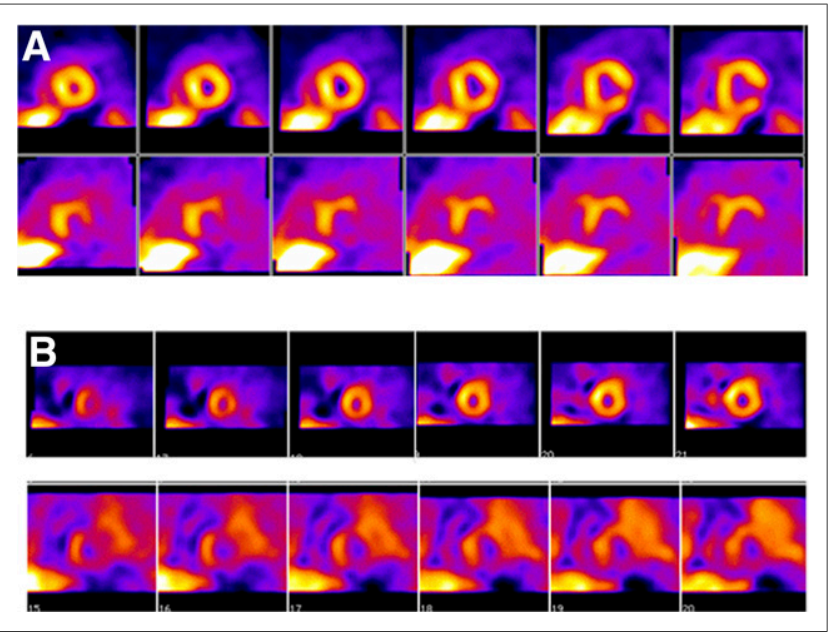

FIGURE 3. SPECT images of innervation (123/-MIBG, bottom row) and

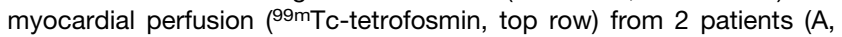
first patient; $B$, second patient) with prior myocardial infarctions who underwent electrophysiologic testing for determination of inducibility of ventricular tachycardia and fibrillation. In both patients, defects on 123|-MIBG imaging were substantially larger than those on perfusion images. Patient shown in B, with global reduction in ${ }^{123}$-MIBG uptake (reflected by high background activity) and larger summed defect score, had positive electrophysiology study. Studies have suggested that large defects on SPECT ${ }^{123}$ I-MIBG scans are associated with increased likelihood of arrhythmic events or implantable cardioverter-defibrillator shocks (38). (Reprinted from (37).)

\section{REFERENCES}

1. Ackerknecht EH. History of the discovery of the vegetative (autonomic) nervous system. Med Hist. 1974;18:1-8.

2. Hanin I, ed. Choline and Acetylcholine: Handbook of Chemical Assay Methods. New York, NY: Raven Press; 1974.

3. Acheson GH, ed. Second symposium on catecholamines. Pharmacol Rev. 1966;18:1-803.

4. Chidsey CA, Braunwald E, Morrow AC. Catecholamine excretion and cardiac stores of norepinephrine in congestive heart failure. Am J Med. 1965;39:442451 .

5. Sole MJ, Lo CM, Laird CW, Sonnenblick EH, Wurtman RJ. Norepinephrine turnover in the heart and spleen of the cardiomyopathic Syrian hamster. Circ Res. 1975;37:855-862.

6. Glowniak JV. Cardiac studies with metaiodobenzylguanidine: a critique of methods and interpretation of results. J Nucl Med. 1995;36:2133-2137.

7. Carrió I. Cardiac neurotransmission imaging. J Nucl Med. 2001;42:1062-1076.

8. Patel AD, Iskandrian AE. MIBG imaging. J Nucl Cardiol. 2002;9:75-94.

9. Bengel FM, Schwaiger M. Assessment of cardiac sympathetic neuronal function using PET imaging. J Nucl Cardiol. 2004;11:603-616.

10. Caldwell JH, Link JM, Levy WC, Poole JE, Stratton JR. Evidence for pre- to postsynaptic mismatch of the cardiac sympathetic nervous system in ischemic congestive heart failure. J Nucl Med. 2008;49:234-241.

11. Blombery PA, Heinzow BGJ. Cardiac and pulmonary norepinephrine release and removal in the dog. Circ Res. 1983;53:688-694.

12. Landsberg L, Young JB. Fasting, feeding and regulation of the sympathetic nervous system. N Engl J Med. 1978;298:1295-1301.

13. Yamashina S, Yamazaki J. Neuronal imaging using SPECT. Eur J Nucl Med Mol Imaging. 2007;34:939-950.

14. Travin MI. Cardiac autonomic imaging with SPECT tracers. J Nucl Cardiol. 2013;20:128-143.

15. Verberne HJ, Brewster LM, Somsen GA, Eck-Smit BL. Prognostic value of myocardial ${ }^{123}$ I-metaiodobenzylguanidine (MIBG) parameters in patients with heart failure: a systematic review. Eur Heart J. 2008;29:1147-1159.

16. Treglia G, Stefanelli A, Bruno I, Giordano A. Clinical usefulness of myocardial innervation imaging using iodine-123-meta-iodobenzylguanidine scintigraphy in evaluating the effectiveness of pharmacological treatments in patients with heart failure: an overview. Eur Rev Med Pharmacol Sci. 2013;17:56-68.

17. Travin MI. Cardiac radionuclide imaging to assess patients with heart failure. 2014;44:294-313.

18. Fallavollita JA, Heavey BM, Luisi AJ Jr, et al. Regional myocardial sympathetic denervation predicts the risk of sudden cardiac arrest in ischemic cardiomyopathy. J Am Coll Cardiol. 2014;63:141-149.

19. Wieland DM, Wu J, Brown LE, Mangner TJ, Swanson DP, Beierwaltes WH. Radiolabeled adrenergic neuron-blocking agents: adrenomedullary imaging with ${ }^{131}$ I-iodobenzylguanidine. J Nucl Med. 1980;21:349-353.

20. Wieland DM, Brown LE, Rogers WL, et al. Myocardial imaging with a radioiodinated norepinephrine storage analog. J Nucl Med. 1981;22:22-31. 
21. Raffel DM, Wieland DM. Development of mIBG as a cardiac innervation imaging agent. JACC Cardiovasc Imaging. 2010;3:111-116.

22. Sisson JC, Wieland DM. Radiolabelled meta-iodobenzylguanidine: pharmacology and clinical studies. Am J Physiol Imaging. 1986;1:96-103.

23. Sisson JC, Shapiro B, Meyers L, et al. Metaiodobenzylguanidine to map scintigraphically the adrenergic nervous system in man. J Nucl Med. 1987;28:1625-1636.

24. Merlet P, Valette H, Dubois-Rande JL, et al. Prognostic value of cardiac metaiodobenzylguanidine imaging in patients with heart failure. J Nucl Med. 1992;33:471-477.

25. Merlet P, Benvenuti C, Moyse D, et al. Prognostic value of MIBG imaging in idiopathic dilated cardiomyopathy. J Nucl Med. 1999;40:917-923.

26. Wakabayashi T, Nakata T, Hashimoto A, et al. Assessment of underlying etiology and cardiac sympathetic innervation to identify patients at high risk of cardiac death. J Nucl Med. 2001;42:1757-1767.

27. Jacobson AF, Senior R, Cerqueira MD, et al. Myocardial iodine-123 metaiodobenzylguanidine imaging and cardiac events in heart failure: results of the prospective ADMIRE-HF (AdreView Myocardial Imaging for Risk Evaluation in Heart Failure) study. J Am Coll Cardiol. 2010;55:2212-2221.

28. Nakata T, Nakajima K, Yamashina $\mathrm{S}$, et al. A pooled analysis of multicenter cohort studies of ${ }^{123} \mathrm{I}$-mIBG cardiac sympathetic innervation imaging for assessment of long-term prognosis in chronic heart failure. JACC Cardiovasc Imaging. 2013;6:772-784.

29. Kasama S, Toyama T, Kumakura H, et al. Effects of perindopril on cardiac sympathetic nerve activity in patients with congestive heart failure: comparison with enalapril. Eur J Nucl Med Mol Imaging. 2005;32:964-971.

30. Kasama S, Toyama T, Kumakura H, et al. Addition of valsartan to an angiotensinconverting enzyme inhibitor improves cardiac sympathetic nerve activity and left ventricular function in patients with congestive heart failure. $\mathrm{J} \mathrm{Nucl} \mathrm{Med}$. 2003;44:884-890.
31. Agostini D, Belin A, Amar MH, et al. Improvement of cardiac neuronal function after carvedilol treatment in dilated cardiomyopathy: a ${ }^{123} \mathrm{I}-\mathrm{MIBG}$ scintigraphic study. J Nucl Med. 2000;41:845-851.

32. Kasama S, Toyama T, Kumakura H, et al. Spironolactone improves cardiac sympathetic nerve activity and symptoms in patients with congestive heart failure. J Nucl Med. 2002;43:1279-1285.

33. Cha YM, Oh J, Miyazaki C, et al. Cardiac resynchronization therapy upregulates cardiac autonomic control. J Cardiovasc Electrophysiol. 2008;19:10451052 .

34. Drakos SG, Athanasoulis T, Malliaras KG, et al. Myocardial sympathetic innervation and long-term left ventricular mechanical unloading. JACC Cardiovasc Imaging. 2010;3:64-70.

35. Verschure DO, Veltman CE, Manrique A, et al. For what endpoint does myocardial ${ }^{123}$ I-MIBG scintigraphy have the greatest prognostic value in patients with heart failure? Results of a pooled individual patient data meta-analysis. Eur Heart J Cardiovasc Imaging. 2014;15:996-1003.

36. Nishisato K, Hashimoto A, Nakata T, et al. Impaired cardiac sympathetic innervation and myocardial perfusion are related to lethal arrhythmia: quantification of cardiac tracers in patients with ICDs. J Nucl Med. 2010;51:1241-1249.

37. Bax JJ, Kraft O, Buxton AE, et al. ${ }^{123}$ I-mIBG scintigraphy to predict inducibility of ventricular arrhythmias on cardiac electrophysiology testing: a prospective multicenter pilot study. Circ Cardiovasc Imaging. 2008;1:131-140.

38. Boogers MJ, Borleffs CJ, Henneman MM, et al. Cardiac sympathetic denervation assessed with 123-iodine metaiodobenzylguanidine imaging predicts ventricular arrhythmias in implantable cardioverter-defibrillator patients. J Am Coll Cardiol. 2010;55:2769-2777.

39. Roger VL, Go AS, Lloyd-Jones DM, et al. American Heart Association heart disease and stroke statistics: 2012 update-a report from the American Heart Association. Circulation. 2012;125:e2-e220. 